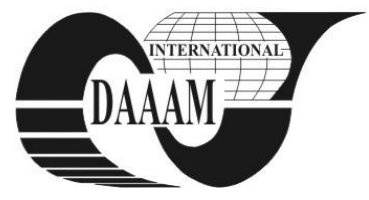

\title{
NONLINEAR PLANT IDENTIFICATION USING HAMMERSTEIN MODEL
}

\author{
BRAZDIL, M[ichal]
}

Abstract: This paper deals nonlinear plant identification using Hammerstein model. The paper consists of two parts. The first part of this paper describes principle of Hammerstein model and its structure. The second part deals with experimental identification of a nonlinear plant using Hammerstein model. Key words: nonlinear plant, experimental identification, Hammertein model, least squares method

\section{INTRODUCTION}

Identification is the most important part of controller design. Two types of plants exist currently. The first type of plants is linear and the second type is nonlinear. Identification and controller design of a linear plant is very easy. However, identification of a nonlinear plant is more difficult.

Nonlinear plants can be found in industry most often. Several methods exist for identification of nonlinear plants. Hammerstin model is a structure for indentification of nonlinear plants. This method is very simple.

\section{HAMMERSTEIN MODEL}

The Hammerstein model is probably the most widely known and applied nonlinear dynamic modeling approach. It assumes a separation between the nonlinearity and the dynamics of the process. The Hammerstein model consists of a nonlinear static block followed by a linear dynamic block. The structure of Hammerstein model is shown in the Fig. 1.

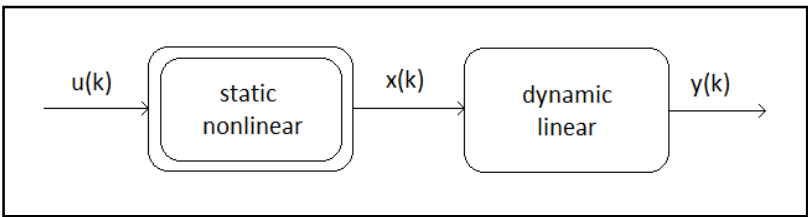

Fig. 1. Hammerstein model structure

This model can be described by the equations

$$
\begin{gathered}
x(k)=q(u(k)) \\
y(k)=b_{1} x(k-1)+\cdots+b_{n} x(k-n) \\
-a_{1} y(k-1)-\cdots-a_{n}(y-n)
\end{gathered}
$$

In order to avoid redundancy, the gain of linear system may be fixed at 1 , which gives the following constraint

$$
\frac{\sum_{i=1}^{n} b_{1}}{1+\sum_{i=1}^{n} a_{i}}=1
$$

The structure describes all systems where the actuator's nonlinearity, for example the characteristics of a valve, the saturation of an electrornagnetic motor, etc., is dominant and other nonlinear effects can be neglected. For this reason Hammerstein models are popular in control engineering.
Furthermore, it is easy to compensate the nonlinear process behavior by a controller that implements the inverse static nonlinear $g^{-1}$ at its output. Another advantage of the distinction into nonlinear and linear blocks is that stability is determined solely by linear part of the model, which can be easily cheched.

The static nonlinearity is classically approximated by a polynomial. Any other static approximator can also be utilized, which indeed is a good idea in order to avoid the inferior interpolation and extrapolation capabilities of polynomials.

\section{NONLINEAR IDENTIFICATION}

This part of the paper deals with application of Hammerstein model structure to nonlinear model of valve. For modeling of a valve and its identification was used software MathWork Matlab. In the Fig. 2. a block scheme of valve is shown. The model of the valve consists of two parts. The first part is a flow meter and second part is a mechanical actuator.

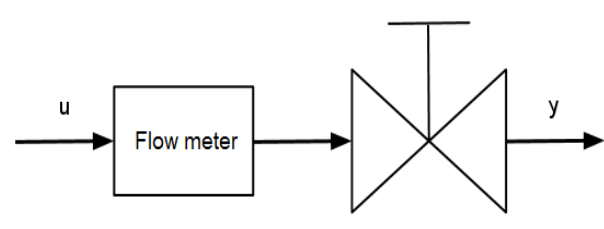

Fig. 2. Block scheme of valve

Simulink scheme of valve was created in MathWork Matlab Simulink. After that, a static characteristic of the valve was measured. A Simulink scheme for measurement of static characteristic is shown in the Fig. 3.

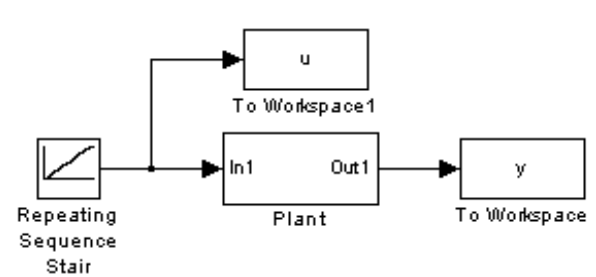

Fig. 3. Simulink scheme for static characteristic measurement

The input signal was voltage from 0 to $1.5 \mathrm{~V}$ with step 0.1 $\mathrm{V}$ and the output signal was flow in $\mathrm{ml} / \mathrm{min}$. The static characteristic of valve is shown in the Fig. 4.

It is obvious from the Fig. 4. that the valve has a nonlinear static characteristic. The structure of Hammerstein model can be used for identification of valve.

The first step for creation of Hammerstein model structure was determined of function $g(u(k))$. This function has to go through points of the static characteristic. The function $g(u(k))$ in the Fig. 4 has a logarithmic trend. 


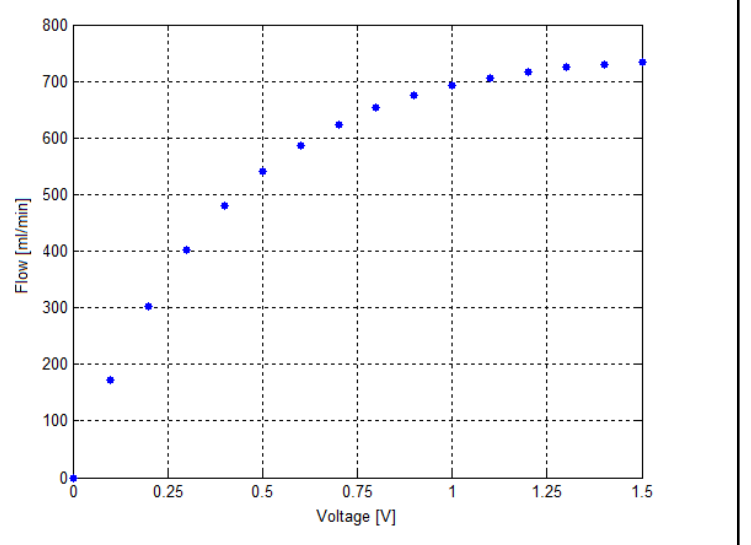

Fig. 4. Static characteristic of valve

The Matlab function fminsearch() was used for finding function $g(u(k))$ that was in the form

$$
g(u(k))=750.36-748.18 e^{-2.56 u(k)}
$$

An approximated static characteristic of valve is shown in the Fig. 5.

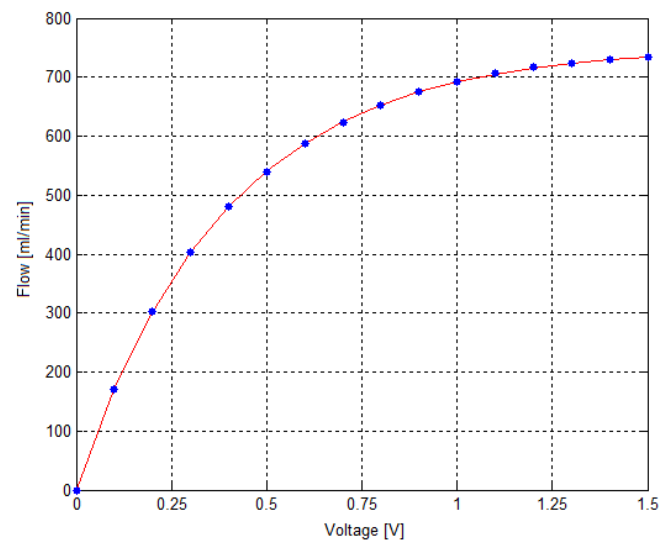

Fig. 5. Approximated static characteristic of valve

The approximated static characteristic of valve serves as a nonlinear block of Hammerstein model (Fig. 6.).

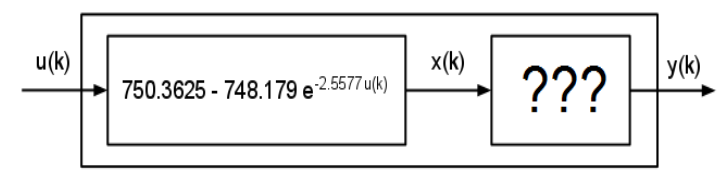

Fig. 6. Hammerstein model with known the nonlinear block

The next step was to determine the linear dynamic block of Hammerstion model structure. The step response of valve is shown in the Fig. 7. The sample time $T_{0}$ was determined from this response.

$$
T_{0}=\left(\frac{1}{6} \div \frac{1}{15}\right) T_{95}=0.3 \mathrm{~s}
$$

The Matlab function $\operatorname{arx}()$ was used for transfer function identification of a linear block. Signals $x(k)$ as input and $y(k)$ as output was used for identification of the linear block.

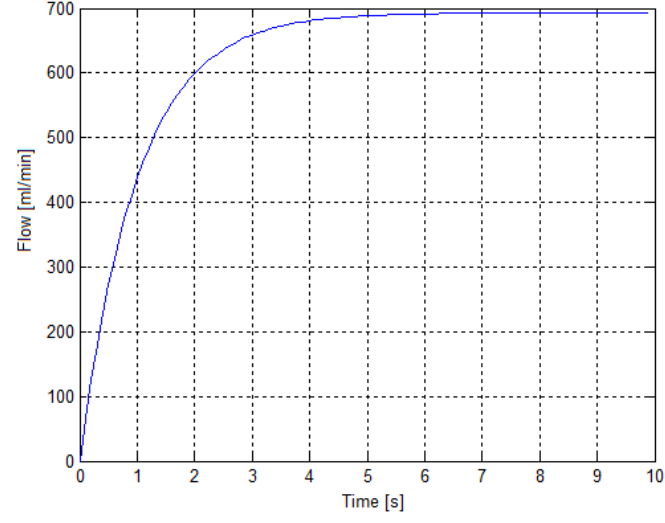

Fig. 7. Step response of valve

The transfer function of the linear block is in the form

$$
G_{S}\left(z^{-1}\right)=\frac{0.2594 z^{-1}}{1-0.74 z^{-1}} \quad T_{0}=0.3 s
$$

Hammerstein model of identified valve is shown in the Fig. 8.

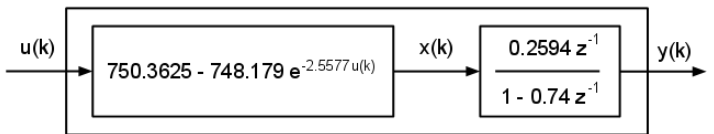

Fig. 8. Hammerstein model of the identified valve

Structure of Hammerstin model is very simple approach for identification and control of nonlinear plants. For controller design only a linear dynamic block is used. For nonlinear part distraction of Hammerstein model must be connected to output of controller inverse function $g^{-1}(u(k))$.

\section{CONCLUSION}

This paper described identification of nonlinear plant using structure of Hammerstein model. The model of nonlinear valve was used for experimental identification. The paper described a procedure of the identification of nonlinear static and linear dynamic parts of Hammerstein model. The result of the identification is a model that can be used for a controller desing.

\section{ACKNOWLEDGEMENTS}

This work was supported in part by the Ministry of Education of the Czech Republic under grant MSM 7088352101 and in part by Tomas Bata University in Zlin under grant IGA/55/FAI/10/D.

\section{REFERENCES}

Nelles, O. (2001). Nonlinear System Identification, Springer, 978-3-540-67369-9, Berlin, pp. 584-585

Söderström, T.; Stoica, P. (1989). System identification, Prentice Hall, 0-13-881236-5, United Kingdom

Ljung, L. (1987). System identification: Theory fro the User, Prentice Hall, 0-13-881640-9,United Kingdom

Giri, F., et al. (2002). Hammerstein model identification. MED 2002, 1, 193, 0-78-036495-3

Al-Duwaish, H.; Naeem, W- (2000). Nonlinear Model Predictive Control of Hammerstein and Wiener models Using Genetic Algorithms. IEEE Conference on Control Aplications, 0-7695-0525-2 